Revista de Filosofía

Volumen 66, (2010) $241-260$

\title{
FILOSOFÍA, EXPERIENCIA Y CONCIENCIA EN LA FENOMENOLOGÍA DEL ESPIRITU. UNA REFLEXIÓN EN TORNO AL MODO DE EXPOSICIÓN DE LA VERDAD FILOSÓFICA SEGÚN HEGEL ${ }^{1}$
}

\author{
Hardy Neumann Soto \\ Pontificia Universidad Católica de Valparaíso \\ hneumann@ucv.cl
}

\begin{abstract}
Resumen
El presente artículo discute, yendo más allá de la reflexión hegeliana, el peculiar sentido que adquiere en Hegel el enunciado "la exposición de la verdad filosófica" (die Darstellung der philosophischen Wahrheit). La determinación del modo de dicha exposición es esencial a la forma en que el objeto deviene efectivamente objeto de la conciencia. Para cumplir con este designio reflexivo se pasa revista a las principales relaciones entre filosofía, el escenario de su manifestación y las nociones allí implicadas, acudiendo principalmente al prefacio de la Fenomenología del Espiritu. La discusión se complementa con pasajes de la Enciclopedia (1827), de la Ciencia de la Lógica y de la Selbstanzeige de la Fenomenología.
\end{abstract}

Palabras clave: filosofía, conciencia, experiencia, Fenomenología del Espíritu, Selbstanzeige.

\section{Abstract}

This article discusses - going beyond Hegel's reflection- the peculiar sense that the sentence "the exposition of the philosophical truth" (die Darstellung der philosophischen Wahrheit) achieves in his writings. The determination of the modus of such exposition is essential to the form in which the object becomes in fact the object of consciousness. To fulfill this reflexive aim we review - mainly in the light of the Preface to the Phenomenology- the central relationships between philosophy, the scene of her manifestation and the notions it implies. The discussion is complemented with texts of the Encyclopedia, the Science of Logic and the Selbstanzeige of the Phenomenology.

KeYwords: philosophy, consciousness, experience, Phenomenology of Mind, Selbstanzeige.

Este trabajo, iniciado en Chile y presentado en una primera versión en el Simposio Internacional en torno a la Fenomenología del Espíritu en el Centro de Filosofía Clásica Alemana en la U. Nacional de Cuyo, debe su término y enriquecimiento bibliográfico a una estadía de investigación en el I. de Filosofía de la U. de Dresden, financiada por la Fundación Alexander-von-Humboldt, a la que hago llegar aquí mi agradecimiento. 


\section{Introducción}

Franz Wiedmann ha expresado que La Fenomenología del Espíritu "representa la culminación del desarrollo filosófico de Hegel, y todos los escritos posteriores, prescindiendo de su importancia inmanente, son, en el fondo, tan solo una ejecución más cuidada, con una articulación más rigurosa y una profundización más sistemática de lo planteado en la Fenomenología del Espíritu" (Wiedmann 1965, p. 34). Si esta aseveración es correcta, dicha obra, a pesar de ser el producto intelectual de un hombre aún joven, constituye, sin embargo, dentro de sus límites, un non plus ultra en el desarrollo intelectual de su autor. Esta circunstancia permitiría operar metodológicamente con la idea de que los pensamientos contenidos en ella constituyen posiciones firmes, correspondientes a las grandes intuiciones que movieron en su totalidad el pensamiento de Hegel, más allá de los necesarios desarrollos y afinamientos a los que hayan podido ser sometidos en los textos posteriores.

Adoptaré aquí el supuesto metodológico antedicho. Operando desde él, pretendo, en lo que sigue, discutir y reflexionar en torno a la relación entre conciencia y experiencia en la Fenomenología del Espíritu de Hegel, intentando fijar en ella el tipo de relato que le corresponde a la exposición filosófica, teniendo plena conciencia de que en Hegel adquiere características peculiares. Pero las consideraciones que aquí se propondrán atañen no solo a la conciencia y la experiencia, sino que afectan esencialmente también a la filosofía como tal, al modo como ella se define y la forma de su exposición. Mi intención no es parafrasear a Hegel, sino prolongar desde él una meditación en torno a la filosofía, la forma de exposición inmanente al sistema hegeliano y las nociones fundamentales de la Época Moderna comprometidas en el título del artículo.

\section{Fenomenología y filosofía}

En el Prefacio a la Fenomenología del Espíritu, agregado, como se sabe, con posterioridad a la redacción del texto, mientras éste ya se encontraba en prensa, Hegel inicia sus reflexiones señalando que en un escrito de corte filosófico parece no solo superfluo (überflüssig) e inadecuado (unpassend), sino incluso contrario al fin (zweckwidrig) y al modo como la investigación filosófica ha de desplegarse, que se den explicaciones en torno al objetivo y la ocasión de la formulación de un proyecto filosófico, así como de las relaciones que éste pueda tener con filosofías precedentes o sincrónicamente concurrentes respecto del tema abordado. La razón en la que Hegel apoya una afirmación semejante podría dar la impresión de que es el fruto de una posición filosófica más, entre otras. Sin embargo, el argumento esgrimido por él estriba en que la exposición de la verdad filosófica [die Darstellung der philosophischen Wahrheit] es, sin más, refractaria al simple enunciado de la meta de la investigación, la mención de la ocasión de su surgimiento y de las posibles relaciones que pueda tener con investigaciones equivalentes. Dicho de otro modo y en fórmula jurídica: estos 
elementos mencionados no empecen la genuina modalidad en que ha de exponerse la verdad filosófica, y a tal punto no lo hacen, que resultan carentes de valor cuando pretenden prestar tal servicio a una verdad de esa naturaleza (cfr. Hegel, PhdG, vol. 2, p. 9). Cabe preguntarse, con todo, ¿por qué no?, ¿cuál es la naturaleza de la verdad filosófica como para que se resista a una exposición en el sentido en que fuera de Hegel se entiende esta expresión? ¿Cómo debe, pues, exponerse esa clase de verdad? ¿Cuál es el rol que le cabe a la conciencia y a la experiencia en esta cuestión? De esto nos haremos cargo ahora.

Lo que está aquí en juego y que concierne directamente al problema que nos ocupa, es el sentido y alcance que tiene la fórmula "exposición de la verdad filosófica". Sin embargo, provisional, o sea anticipativamente, observemos que la falta de vigor de los elementos antes indicados, considerados sin trabazón interna, se halla en que la filosofía o, más precisamente, la verdad filosófica, está supeditada a una modalidad de exposición, que, en su virtud, es ajena a una lógica que, dicho con Heidegger, se revela como "zaguera" (Heidegger 1986, p. 10.), vale decir, simplemente reproductora de contenidos y, en consecuencia, improductiva. Hegel insiste a este respecto que "lo que sería adecuado decir en un prólogo acerca de la filosofía, y cómo decirlo [...] no puede valer para el modo y la manera en que debe exponerse la verdad filosófica" (Hegel, $P h d G$, p. 9) ${ }^{2}$. Tal sería el caso si se tratase de una mera historiografía y no de una historia de la verdad filosófica (en sentido fuerte hegeliano), distingo claramente expresado cuando se hace entrar en juego los términos alemanes Historie y Geschichte.

En los demás saberes -que hoy llamamos ciencias particulares- lo que se expone es el fin o los resultados de la investigación. Y no se trata de que en filosofía no tengamos que habérnoslas también con ellos, pero en el enfoque hegeliano, no importan los resultados independientes, esto es, los frutos externos y posteriores a la actividad que a ellos conduce. Cabe consignar que esta última postura, aunque no deja de tener algún resabio aristotélico, en la noción de enérgeia, no coincide del todo con ella. Para Hegel se trata de una exposición en el modo de un mostrar deviniente, donde lo que queda subrayado no es tanto el acto de mostrar, cuanto el devenir mismo (Werden), pues solo si hay acontecimiento o devenir hay posibilidad de mostrar algo. El mostrar se monta sobre el devenir. El despliegue deviniente permite que la cosa se ponga "en marcha hacia sí misma" ${ }^{3}$. Resuenan aquí palabras de Platón, quien hablaba

2 "Denn wie und was von Philosophie in einer Vorrede zu sagen schicklich wäre [...] kann nicht für die Art und Weise gelten, in der die philosophische Wahrheit darzustellen sei" (todas las traducciones de los textos en alemán son del autor del artículo).

3 Hay que consignar que este "venir de la cosa hacia sí misma" no es equivalente al despliegue de lo que la cosa ya siempre era (tò tí ên eînai), como en Aristóteles, pues en este caso la cosa se despliega desde sí misma y su ser está resguardado por su esencia; no corre peligro alguno en lo que toca a las configuraciones de su ser. En Hegel, por el contrario, la cosa se ex-pone teniendo que ganarse a sí desde sí, esto es, ganar su sí mismo en la exterioridad. 
de una periagogé del alma, en que ella se remonta desde una forma habitual de desenvolverse hacia estadios en que alzándose -superando diría Hegel- por sobre el mundo sensible, es transportada hasta el mundo inteligible. El alma ha de ascender hacia la luz como quien pasa "desde un día sombrío hasta un día verdadero; o sea, un camino de ascenso hacia la realidad, camino al que podemos llamar filosofía" (cfr. Platón, República, 521c). Así también acontece en la filosofía fenomenológica de Hegel: la cosa ha de llegar a sí misma pero teniendo en cuenta que ella "no se agota en su fin, sino en su ejecución" ( $P h d G$, p. 10). Esta afirmación sugiere asociar el resultado -la cosa- al todo, en la medida en que en el todo se halla el resultado. El resultado es ciertamente un todo, pero un todo infecundo mientras no sea "todavía el todo efectivamente real" (ibíd.); sólo llega a ser propiamente resultado cuando "lo es a la par con su devenir" (ibíd.). Hegel concluye aquí que el fin por sí mismo, vale decir, aislado, "es lo universal carente de vida, así como la tendencia es el mero impulso que aún esquiva su realidad efectiva; y el nudo resultado es el cadáver que la tendencia deja tras de sí" $(P h d G, \text { pp. 10-11) })^{4}$. O sea, separadamente, ni la tendencia ni el resultado de ésta es propiamente real efectivo (wirklich), vale decir, ninguno de los dos produce efectos. Separados entre sí, la una -la tendencia-es privación de la realidad a la que tiende; el otro -el resultado- al que la tendencia se dirige, es un correlato palidecido, cadavérico, de la tendencia. Puede observarse, pues, que Hegel no le otorga peso ni a la tendencia ni al resultado, ni tampoco a lo que simplemente estaría al medio de ambos, sino que acoge, a una, a los dos. Esta es una de las particularidades del proceder dialéctico-especulativo, que nos ocupará brevemente más adelante.

En el mismo contexto se da expresión, siempre en la Fenomenología, a una idea que se encuentra repetida también en la Ciencia de la Lógica, y que sirve de resumen de lo planteado. Ese pensamiento se exterioriza así: "Das Bekannte überhaupt ist darum, weil es bekannt ist, nicht erkannt" (PhdG, p. 26). Se lo traduce fácilmente por "lo conocido en términos generales, precisamente por ser conocido, no es reconocido" 5 . Pero creo que aquí hay que efectuar algunas puntualizaciones: primero, no hay lo conocido "en términos generales"; no se trata de un conocimiento en general, sino de un conocimiento de algo como tal; es lo que expresa el adverbio überhaupt en el texto alemán. Lo que Hegel quiere decir es justamente que no se conoce algo efectivamente cuando está reconocido. Habría que decir, más bien, que algo es conocido cuando "llega a ser reconocido". Este es el sentido del verbo "erkennen", que implica movimiento en la consecución de aquello hacia lo que se tiende: lo conocido. Hegel

$4 \quad$ "Denn die Sache ist nicht in ihrem Zwecke erschöpft, sondern in ihrer Ausführung, noch ist das Resultat das wirkliche Ganze, sondern es zusammen mit seinem Werden; der Zweck für sich ist das unlebendige Allgemeine, wie die Tendenz das bloße Treiben, das seiner Wirklichkeit noch entbehrt; und das nackte Resultat ist der Leichnam, der die Tendenz hinter sich gelassen".

5 Así traduce W. Roces (Hegel, Fenomenología del Espíritu, p. 23). Jiménez Redondo vierte, por su parte: "Lo familiar, precisamente por sernos familiar, no es algo que conozcamos” (Georg Wilhelm Friedrich Hegel, Fenomenología del Espíritu, p. 135). 
agrega que "es la ilusión más corriente en que uno incurre y el engaño que se hace a otros el dar por supuesto en el conocimiento algo como conocido y conformarse con ello; pese a todo lo que se diga y se hable, esta clase de saber, sin que nos demos cuenta por qué, no se mueve del sitio" ( $P h d G$, pp. 26-27). Los ejemplos conceptuales dados por Hegel asociados al pasaje citado son de referencia mutua: sujeto-objeto, Dios-naturaleza, entendimiento-sensibilidad. Por tanto, si alguna clase de movimiento se da entre ellos, cuando se los declara conocidos y no reconocidos, éste es superficial. Vale decir, supone los relatos ya constituidos y, por tanto, no hay propiamente devenir. Así concebidos, hay falta de especulación en sentido técnico hegeliano. Ahora bien, dado que la filosofía se desenvuelve "esencialmente en el elemento de la universalidad" (PhdG., p. 9) ${ }^{6}$ da la impresión de que es a ella a quien convendría, especialmente y en propiedad, una exposición de los resultados a los que debe llegar; solo entonces y allí se encontraría la "cosa misma", mientras que el proceso que a ello conduce parecería representar algo inesencial (cfr. ibíd.). La filosofía se mueve ciertamente en el elemento de lo universal porque no habla propiamente de cosas, como árbol, perro o ventana $^{7}$. Cuando se introducen deícticos para determinar más de cerca estas expresiones, el movimiento fenomenológico, o sea, aquí, mostrativo, inherente a la certeza sensible, hace ver que esas determinaciones siguen siendo universales, pues este aqui no es el árbol, sino una casa; este ahora no es el mediodía, sino la noche, etc. (cfr. $P h d G$, pp. 64 y 65). Pero el desenvolvimiento de la filosofía en el elemento de lo universal no es óbice alguno para que ella decante sus verdades en el modo del devenir; pues la filosofía no está llamada a quedarse en la inmediatez de la universalidad, sino que tiene que ganarse a sí misma precisamente por la vía de eso que Hegel, dándole un sentido técnico fuerte y restricto a la expresión, denomina Darstellung, exposición. En la Ciencia de la Lógica, en un pasaje en el que previamente se ha tenido presente a la Fenomenología del Espíritu como uno de los lugares donde se ha dado un ejemplo concreto de la acción del método dialéctico ${ }^{8}$, a saber, en la conciencia, se dice incluso que "es claro que no pueden pasar por científicas aquellas exposiciones [Darstellungen] que no siguen la marcha de este método y su simple ritmo, pues esa es la marcha de la cosa misma"(WdL (1832), vol. 3, p. 38) ${ }^{9}$. Desde la óptica de la Ciencia de la Lógica no hay propiamente distinción entre exposición y ciencia. Y aunque, por otra parte, desde la perspectiva de la Fenomenología, no es posible, sin más, mantener tal

6 "[...] weil die Philosophie wesentlich im Elemente der Allgemeinheit ist".

$7 \quad$ Cfr. también al respecto, Dri 2006, p. 26: "El medio o ambiente en el que se desarrolla el quehacer filosófico es lo universal-das Allgemeine- porque no trata de cosas, objetos, realidades muertas, ahistóricas, sino del espíritu-Geist- que siempre es universal llevando en su seno lo particular-das Besondere".

8 "Ich habe in der Phänomenologie des Geistes ein Beispiel von dieser Methode, an einem concretern Gegenstande, an dem Bewußtseyn, aufgestellt” (Hegel, WdL, vol. 3, p. 37).

9 "Es ist klar, daß keine Darstellungen für wissenschaftlich gelten können, welche nicht den Gang dieser Methode gehen und ihrem einfachen Rythmus gemäß sind, denn es ist der Gang der Sache selbst". 
identificación ${ }^{10}$, mucho más las disocia el punto de vista natural de la filosofía, la que cuasi husserlianamente podría llamarse die natürliche Einstellung, la actitud natural. La razón es que ésta tiende a mantener en distancia filosofía y cosa y, por tanto, exposición y ciencia. En efecto, la conciencia, como conciencia natural, distingue sin cuestionamientos entre sí misma y su objeto, entre su identidad y la identidad del objeto, o sea, entre dos identidades que en tanto afirmen cada una lo que creen ser, son aparentemente irreconciliables. La pregunta de fondo aquí es, ¿cómo puede este último, el objeto, llegar a ser efectivamente el objeto de la conciencia, deviniendo así suyo? Pues bien, la fenomenología del espíritu es el intento de superación de estos dos reinos primero naturalmente contrapuestos. Exposición no quiere decir aquí, en consecuencia, la narración externa de las ideas filosóficas dentro de sus respectivos sistemas. La opinión del antagonismo entre lo verdadero y lo falso "no concibe la diversidad de los sistemas filosóficos como el desarrollo progresivo de la verdad, sino que sólo ve en la diversidad la contradicción" (PhdG, p. 10) ${ }^{11}$.

Para Hegel, la serie de las configuraciones que va recorriendo la conciencia es la historia de la formación acabada de la conciencia misma hacia la ciencia ${ }^{12}$. Esta afirmación puede entenderse referida nada más que a la conciencia en el sentido de toda conciencia, esto es, cualquier conciencia; pero también puede entenderse que hay allí una referencia a la historia de la conciencia. Me parece que los dos sentidos son válidos. Toda conciencia como conciencia natural -y de ésta habla Hegel de modo específico en todo el párrafo correspondiente- recorre una historia en cuya virtud aquélla va cobrando figura. El vocablo alemán del que hace uso Hegel cuando habla de "historia de la formación de la conciencia" es Geschichte, vale decir, historia en el sentido de acontecimiento. Pues bien, una sucesión de acontecimientos o acontecimientos sucesivos da lugar no solo a la constitución del objeto de la conciencia, sino, a una con ello, a la conciencia misma; por eso en la fenomenología hay no solo saber de las figuras de la conciencia, sino de las con-figuraciones de la misma, la conciencia

10 No se pueden asimilar del todo si se tiene presente que desde la Ciencia de la Lógica el reino de lo lógico "es la verdad, tal como ella es en y por sí misma sin velo; se puede por ello expresar que este contenido es la exposición de Dios, tal como él es en su eterna esencia, antes de la creación de la naturaleza y de un espíritu finito" ("die Wahrheit, wie sie ohne Hülle an für sich selbst ist; man kann sich deßwegen ausdrücken, daß dieser Inhalt die Darstellung Gottes ist, wie er in seinem ewigen Wesen, vor der Erschaffung der Natur und eines endlichen Geistes ist") (WdL (1832), p. 34).

11 "So fest der Meinung der Gegensatz des Wahren und des Falschen wird, so pflegt sie auch entweder Beistimmung oder Widerspruch gegen ein vorhandenes philosophisches System zu erwarten und in einer Erklärung über ein solches nur entweder das eine oder das andere zu sehen".

12 "Die Reihe seiner Gestaltungen, welche das Bewußtsein auf diesem Wege durchläuft, ist vielmehr die ausführliche Geschichte der Bildung des Bewußtseins selbst zur Wissenschaft" ( $P h d G$, p. 56). "La serie de sus configuraciones, que por esta vía recorre la conciencia, es más bien la historia completa de la formación de la conciencia misma hacia la ciencia". 
vive autoconstituyéndose en sus configuraciones (Gestaltungen). En la particularidad, éstas sobreviven solo un instante, pero en la totalidad se recogen todas. Se asiste también en ese pasaje, por otra parte, al uso del término historia en el sentido común y corriente de la palabra, pero en la base del mismo sigue estando siempre el acontecer (Geschehen) de las figuras, en este caso ya no de la mera conciencia, sino del espíritu. El propio Hegel, por supuesto, se siente partícipe de "tiempos de gestación y de transición hacia una nueva época". Y en tono universal añade: "El espíritu ha roto con el mundo anterior de su ser allí y de su representación y se dispone a hundir eso en el pasado, entregándose a la tarea de su propia transformación" (PhdG, p. 14). Tanto el individuo como el espíritu del mundo han recorrido pacientemente las formas y han asumido la inmensa labor de la historia de ese mismo mundo, en que el espíritu se derrama (cfr. PhdG, p. 25) o, dicho con Hegel, se objetiva. Por consiguiente, "toutes les déterminations universelles de l'existence se présentent comme des figures de la conscience, dans la Phénoménologie ou dans la philosophie de l'histoire" (Hyppolite, 1961, p. 116).

Volviendo, pues, al problema que nos ocupa, la exposición en tanto que narración o relato, tiene lugar tan solo una vez que están consumadas (verwirklicht) las condiciones que la posibilitan, vale decir, una vez que haya efectivamente algo que mostrar, que haya una historia acaecida o un acaecimiento histórico que pueda ser contado, ex-puesto. Este acontecimiento es, en la Fenomenología, ciertamente histórico en el primer sentido indicado, pero a su turno es un acontecer del saber como acontecer que sabe o acontecer sapiente. Hegel expresa esta correlación mediante el fecundo verbo werden en su forma substantivada, en unidad aquí con el término Wissenschaft. Así dice el autor: "Dies Werden der Wissenschaft überhaupt oder des Wissens ist es, was diese Phänomenologie des Geistes darstellt", o sea, "este llegar a ser [devenir] de la ciencia como tal o del saber es lo que esta Fenomenología del Espíritu expone" (PhdG, p. 31). Pero este saber acontece al menos de manera doble: por una parte, es exposición, o sea, explicitación desplegante del saber que aparece (cfr. $P h d G$, p. 58$)^{13}$, porque tiene a este saber como su objeto (cfr. $P h d G$, p. 55) ${ }^{14}$. Por otra parte, este saber no puede ser mera aprehensión puntual, sino sucesiva, vale decir tiene que superar la mera aprehensión de lo que aparece, del fenómeno, para transformarse en algo cualitativamente superior, a saber, en experiencia. No hay, por eso, propiamente, ni una exposición ni, mucho menos, una experiencia puntual. Lo

13 "Diese Darstellung, als ein Verhalten der Wissenschaft zu dem erscheinenden Wissen und als Untersuchung und Prüfung der Realität des Erkennens vorgestellt [...]".

14 "Weil nun diese Darstellung nur das erscheinende Wissen zum Gegenstande hat, so scheint sie selbst nicht die freie, in ihrer eigentümlichen Gestalt sich bewegende Wissenschaft zu sein, sondern sie kann von diesem Standpunkte aus als der Weg des natürlichen Bewußtseins, das zum wahren Wissen dringt, genommen werden, oder als der Weg der Seele, welche die Reihe ihrer Gestaltungen, als durch ihre Natur ihr vorgesteckter Stationen, durchwandert, daß sie sich zum Geiste läutere, indem sie durch die vollständige Erfahrung ihrer selbst zur Kenntnis desjenigen gelangt, was sie an sich selbst ist". 
puntual atenta contra la posibilidad de despliegue de la verdad. A modo de ilustración de este hecho sirve toda frase en que se tome al absoluto como sujeto sin haber acompañado su desarrollo. Pero "aquella anticipación de que el absoluto es sujeto, no sólo no es, por eso, la realidad efectiva de este concepto, sino que lo hace incluso imposible; pues aquella lo pone como punto quieto, pero éste es el automovimiento" (PhdG, p. 21) ${ }^{15}$.

La fenomenología no es mera ciencia, sino ciencia en general, o sea ciencia como tal. Ella encarna lo científico de la ciencia, no en el sentido en que hoy comprendemos la ciencia y lo científico. Se trata de la Wissenschaft überhaupt, que mienta die philosophische Wissenschaft, la ciencia filosófica. Solo ella es adecuada al "espíritu". Hegel dice, en efecto, en un bello pasaje de resonancia cuasi platónica, que la fenomenología puede ser considerada como "el camino del alma, que recorre la serie de sus configuraciones como estaciones trazadas por su naturaleza, ella se depura en dirección hacia el espíritu, en la medida en que alcanza mediante la experiencia completa de sí misma el conocimiento de aquello que en sí misma es" ( $P h d G$, p. 55). Como tal, ya no puede ser mera exposición del fenómeno y sus formas, sino experiencia, pero experiencia en el modo de la ciencia, experiencia científica. Esta experiencia científica tiene, a una, que saber su objeto y su saber, o sea, (tiene que) saber que sabe.

En la Ciencia de la Lógica de 1812 Hegel introduce el tema de esta ciencia señalando que -al igual que el concepto de ella-, el objeto de la lógica, el pensar, ha de ser tratado esencialmente dentro de ella. A partir de ahí se entiende que Hegel llame al pensar mismo - como él dice, "de una manera más determinada"- "das begreiffende Denken" (WdL (1812-13), Einleitung, p. 15). Esta expresión no puede traducirse aquí simplemente como pensar conceptual o comprensor, sino que se trata del pensar que recoge o agarra en su unidad la totalidad, incluidas las contradicciones y a sí mismo. Por consiguiente, el propio concepto del objeto de la lógica -el pensar- "se produce en su transcurso" [erzeugt sich in ihrem Verlaufe] (ibíd.) y, por tanto, en una introducción a la lógica, en sentido hegeliano, no puede ser expuesto anticipativamente (cfr. ibíd. $)^{16}$.

Es importante agregar a lo señalado por estas tesis de Hegel que algo llega a ser efectivamente conocido no simplemente cuando se conoce verdaderamente, $\sin$

15 "Jene Antizipation, daß das Absolute Subjekt ist, ist daher nicht nur nicht die Wirklichkeit dieses Begriffs, sondern macht sie sogar unmöglich; denn jene setzt ihn als ruhenden Punkt, diese aber ist die Selbstbewegung".

16 Todo el pasaje correspondiente dice así: "Nicht nur aber die Angabe der wissenschaftlichen Methode, sondern auch der Begriff selbst der Wissenschaft überhaupt gehört zu ihrem Inhalte, und zwar macht er ihr letztes Resultat aus; was sie ist, kann sie daher nicht voraussagen, sondern ihre ganze Abhandlung bringt dies Wissen von ihr selbst erst als ihr Letztes und als ihre Vollendung hervor. Gleichfalls ihr Gegenstand, das Denken oder bestimmter das begreifende Denken, wird wesentlich innerhalb ihrer abgehandelt; der Begriff desselben erzeugt sich in ihrem Verlaufe und kann somit nicht vorausgeschickt werden". 
errores o con certeza, sino cuando la conciencia sabe que sabe y lo sabe con verdad; eso es precisamente lo que la define como conciencia; pero cuando esto ocurre ésta desaparece como tal y pasa a ser autoconciencia, cuestión que se refleja en la propia arquitectura de la Fenomenología. Como dice X. Zubiri: "A la verdad compete no solamente la cosa, sino también mi saber de ella. No basta con que una cosa material y brutamente sea verdad, sino que es menester que el entendimiento, que ha entendido algo con verdad, sepa que eso efectivamente es verdad. Por tanto, la verdad compete a una a las cosas y al saber de ellas y la verdad es $a$ una -no sólo por algún acoplamiento externo -cosa y saber" (Zubiri 1994, p. 252).

Un barrunto de este tipo de saber -en el sentido de saber de su saber-y que es claramente trascendental, al modo en que lo definió Kant, se encuentra en Descartes. La alusión a Descartes es relevante, pues sabemos que Hegel alaba a aquél como ese héroe del pensamiento "que ha echado a andar la cosa nuevamente desde el inicio y que sólo él ha constituido de nuevo el suelo de la filosofía" (VGPh., Werke, 20, p. 123) y con el que "entramos propiamente en una filosofía independiente, que sabe que ella proviene autónomamente de la razón y que la autoconciencia es momento esencial de lo verdadero" (op. cit. p. 120) ${ }^{17}$.

Recordemos primero qué decía Kant acerca de lo trascendental. "Trascendental" es un predicado que se aplica al conocimiento cuando éste cumple las condiciones de la correspondiente definición. Así, en la Crítica de la razón pura puede leerse: "Llamo trascendental a todo conocimiento que se ocupa como tal no tanto de objetos, sino de nuestro modo de conocimiento de objetos, en cuanto éste ha de ser posible $a$ priori" (KrV, A 11, B 25: $)^{18}$. "Un sistema de tales conceptos - en realidad debería decir aquí »de tal modo de conocimiento ${ }^{19}$ - se llamaría filosofía trascendental" (ibíd.) ${ }^{20}$.

17 "Wir kommen eigentlich jetzt erst zur Philosophie der neuen Welt und fangen diese mit Cartesius an. Mit ihm treten wir eigentlich in eine selbständige Philosophie ein, welche weiß, daß sie selbständig aus der Vernunft kommt und daß das Selbstbewußtsein wesentliches Moment des Wahren ist". El texto continúa así: "Aquí, podemos decir, nos hallamos en casa y podemos gritar »tierra«, como el navegante tras largo viaje de un lado a otro por el tempestuoso mar; Descartes es uno de los hombres que han empezado con todo desde el principio; y con él empieza la formación [o la cultura], el pensamiento de la época moderna" ["Hier, können wir sagen, sind wir zu Hause und können wie der Schiffer nach langer Umherfahrt auf der ungestümen See »Land« rufen; Cartesius ist einer von den Menschen, die wieder mit allem von vorn angefangen haben; und mit ihm hebt die Bildung, das Denken der neueren Zeit an"].

18 "Ich nenne alle Erkenntnis transzendental, die sich nicht sowohl mit Gegenständen, sondern mit unserer Erkenntnisart von Gegenständen, sofern diese a priori möglich sein soll, überhaupt beschäftigt".

19 La expresión "conceptos" es un resto de la versión en A, que decía que el conocimiento trascendental se ocupa "no tanto de objetos, sino de nuestros conceptos a priori" (el subrayado es mío). Por eso, a continuación concordantemente se decía: "un sistema de tales conceptos [...]. Kant no lo cambió en B.

20 "Ein System solcher Begriffe würde Transzendental-Philosophie heißen". 
Para Kant, Descartes sigue preso de una metafísica dogmática. Pero aún así puede morigerarse esta crítica si acaso es posible mostrar que el filósofo francés fue capaz al menos de moverse en el dominio de lo trascendental, aunque no todavía en el conocimiento trascendental, que implicaría lo que a su turno inició y desarrolló Kant. Este moverse de Descartes en el ámbito de lo trascendental tiene lugar no directamente en el cogito mismo como condición del descubrimiento de la existencia del sí mismo, sino en lo en él implícito para el saber filosófico. En efecto, luego de haber llegado a la certeza de la propia existencia en el acto de pensar y recordarlo en la Tercera Meditación, diciendo "sé con certeza que soy una cosa que piensa" (AT VII, 33), Descartes se pregunta “¿no sé acaso también lo que se requiere para estar cierto de algo?” (ibíd.). Esta pregunta no es simplemente retórica, pues no directa pero sí oblicuamente hay contenida en la certeza de la propia existencia la ratio formalis de la certeza misma, como quiera que en el cogito mismo va inclusa no solo una certeza particular sino los rasgos definitorios de la certeza como tal, o sea, de toda certeza, independientemente de cuál sea la certeza del caso. La objetivación de ese subproducto del cogito-que no ha de entenderse al modo de los corolarios de Spinoza- se vuelve explícito cuando se aclara que "en este primer conocimiento no hay contenida más que una aprehensión clara y distinta de lo expresado por mí" (AT VII, 33). Sabemos que a partir de ahí se obtiene el criterio general de verdad, según el cual "es verdadero todo lo que percibo de modo absolutamente claro y distinto" (ibíd.). Es necesario tener en cuenta que aunque es posible una formalización del mismo, el criterio ha de tener siempre ante la vista el modelo de clarividencia de la certeza, que es el cogito mismo. En otras palabras, puedo asentir a la verdad de algo si y solo si ese algo se me presenta con la misma claridad y distinción con que se me presentó mi existencia en el acto de pensar o dudar ${ }^{21}$. Pues bien, lo que Hegel hereda de Descartes, refinándolo, es esa cierta modalidad con que la conciencia ha de dirigirse a sus objetos. En lo que tiene de modalidad es trascendental, pero en lo que tiene de contenido, el avance hegeliano es cartesiano. Pero Hegel destaca más fuertemente que Kant el cogito cartesiano en la medida en que, en él, es el saber que sabe y que se sabe a sí mismo con certeza, el que se convierte en un saber en el que las cosas aparecen bajo la formalidad de la conciencia. Obsérvese que esta expresión no quiere decir ni de lejos que la conciencia sea pura formalidad, sino que, en su virtud, por el contrario, la conciencia es formalizante. Ella es formalizante de las cosas, a tal punto que éstas tienen que asumir justo la forma de la conciencia. Tendríamos que inventar en español un neologismo para expresar este fenómeno y decir que las cosas aparecen en tanto llegan a ser "concienzadas" (cum-scientia), y en este sentido (co)sabidas, "saboreadas" por la conciencia. El énfasis radica ahora en que ese ser "conscientemente sabidas" - gewußt, en alemán- no es propiamente una formalidad de las cosas, sino aquella que les impone la conciencia misma. La forma impuesta a la conciencia es el concepto. Pero éste -lo sabemos- no se halla al inicio, sino al final. "La meta -dice Hegel-es la penetración del espíritu en

21 Para Heinrich Scholz es el verbo dudar y no pensar el que manifiesta más acabadamente la certeza del cogito. Cfr. Scholz (1931), especialmente pp. 139 y ss. 
lo que es el saber. La impaciencia exige lo imposible, a saber, alcanzar la meta sin los medios" (PhdG, p. 25) 22 . Se trata pues de saber con certeza acerca de los objetos, y esto se logra en el concepto. Es una certeza, como ya lo hemos anticipado, que, aunque parezca paradójico, hay que com-probar, o sea, que hay que probar con otros y en otros. La manera de hacerlo es deviniendo otra -alterándose- la propia conciencia y acogiendo casi ingenuamente lo que es ajeno al saber (Wissen), o sea ajeno a la conciencia misma (Bewußtsein). Ese tipo de prueba es el que se hace en la experiencia. Para llegar a captar su objeto -no simplemente captar de súbito, porque no hay tal- la conciencia tiene que acompañar a éste. La fenomenología se encarga de describir ese proceso de acompañamiento, más precisamente de autoacompañamiento. Pero ocurre que al acompañar su objeto, la conciencia resulta ser acompañada por sí misma; la conciencia se vuelve autocompañía. La verdad de la que se puede hablar aquí, correspondientemente, no es ni concordancia ni mera constancia de la nuda presencia del objeto, sino concomitancia de conciencia y objeto.

\section{El despliegue fenomenológico en su escenario}

La pregunta que cabe hacerse a continuación es la siguiente: ¿cuál es el escenario de la exposición de la que se ha hablado o con qué se relaciona una exposición de la verdad filosófica? La respuesta a esta pregunta ya se ha obtenido implícitamente en virtud de lo que hasta aquí se ha ganado. Ese escenario es la experiencia. La palabra experiencia tiene no solo una larga data, sino que el recurso a ella es frecuente en filosofía, a tal punto que puede hacerse una historia de ésta teniendo como hilo conductor lo que los distintos pensadores han sostenido a su respecto. En Hegel, sin embargo, al igual que a propósito de la noción de Darstellung (exposición), el abordaje de la experiencia no implica acumular una concepción más acerca de ella. La experiencia responde, como casi todos los conceptos hegelianos, a un concepto vivo; esto significa que no es captable sino en el despliegue de esa su vitalidad configurativa.

La exposición del saber de la conciencia y sus figuras, a la que se asiste en la Fenomenología del Espíritu, tiene lugar en la experiencia, y tanto lo expuesto como lo que se recoge en ella puede ser llamado provisionalmente, desde el lado de la conciencia, lo escible, o, más cerca de Hegel, la región de lo conceptuable, vale decir, todo el ámbito de aquello que se puede saber, y que, en principio, lo es todo, porque hegelianamente se trata del absoluto. Una exposición de este tipo que recoge y acoge lo escible o conceptuable es la experiencia.

Ahora bien, para que haya experiencia tiene que tener lugar una apertura en la que el sujeto de experiencia exponga lo que llega a saber. Pero esa exposición no se

22 "Das Ziel ist die Einsicht des Geistes in das, was das Wissen ist. Die Ungeduld verlangt das Unmögliche, nämlich die Erreichung des Ziels ohne die Mittel”. 
hace para que se muestre o destaque el sujeto de la exposición. Más bien, es al revés, el sujeto exponente o experienciante tiene que desaparecer para que sea fecundado por la alteridad de aquello que expone o llega a saber. A una cuestión de este tipo, aunque no por la vía de una mera narración o descripción, se asiste en la Wissenschaft der Phänomenologie des Geistes, en la ciencia de la Fenomenología del Espíritu, entendida justamente como Lehre von den Erscheinungen, como ciencia de los fenómenos.

La expresión Lehre von den Erscheinungen es equívoca: Primero, porque podría entenderse que en ella se trata de los fenómenos de la conciencia, en el sentido de fenómenos psicológicos, ya que la ciencia expuesta es de la experiencia de la conciencia. Pero, a su turno, aunque en la Fenomenología no se trata propiamente de esto, de algún modo esa clase de fenómenos queda recogido en ella, de otra manera, por la vía de su transformación o de su reconducción a formas más elevadas de la misma. Así lo confirma la Selbstanzeige de la Fenomenología del Espíritu, esa suerte de presentación resumida, redactada para la Editorial Jos. Ant. Göbhardtschen, que presumiblemente escribió el propio Hegel $^{23}$. Allí se dice que la Fenomenología del Espíritu "ha de ocupar el lugar de las explicaciones psicológicas o también de las discusiones más abstractas respecto de la fundamentación del saber" (Selbstanzeige, p. 446).

La expresión Lehre von den Erscheinungen es equívoca-segundo- porque podría entenderse que la doctrina en cuestión se aboca únicamente a fenómenos en el sentido de lo solo aparente. Y es cierto que no se trata solo de apariencias, pero también éstas quedan asumidas cuando se las supera en la figura consecutiva correspondiente que las muestra en su verdad. Todo esto denota que aquello que se llama objeto, en virtud de la experiencia, en el sentido en que lo abordaremos un poco más adelante, tiene que negarse a sí mismo en su identidad.

Dado que aquí estamos efectuando una suerte de formalización de lo expuesto por Hegel, se le impone en ese respecto a la fenomenología, ya no solo como obra, sino como el acontecimiento de despliegue de los fenómenos, una tarea que es, desde el punto de vista de las reglas de la lógica formal, no solo "contraintuitiva", como se diría hoy, sino derecha y provocadoramente contradictoria: la tarea de hacer que el objeto deje de ser lo que es. ¿Y qué es el objeto? El objeto es ob-iectum, en alemán

23 Véase al respecto las indicaciones que se efectúan en la página 471 de la Edición aquí utilizada de la Fenomenología del Espíritu: Georg Wilhelm Friedrich Hegel. Hauptwerke in sechs Bänden, Band 2, Phänomenologie des Geistes. Felix Meiner Hamburg, 1999. Esta edición reproduce el texto con la misma paginación del tomo 9 editado por Wolfgang Bonsiepen und Reinhard Heede (Edición histórico-crítica Georg Wilhelm Friedrich Hegel. Gesammelte Werke, in Verbindung mit der Deutschen Forschungsgemeinschaft hrsg. v. der Rheinisch-Westfälischen Akademie der Wissenschaften). Allí se indica que puede asumirse con gran probabilidad que el texto de la Selbstanzeige fue redactado por el propio Hegel. Esto se colige del hecho de que el anuncio apareció primero en el diario en cuyo redactor se había convertido Hegel luego de su partida de Jena. 
Gegen-stand. Estáticamente comprendido su naturaleza es la de un enfrentamiento, el objeto es un estar-al-frente. La única manera para que él deje de enfrentársenos o enfrentarse a la conciencia, a quien mira como lo otro de sí, es acogiéndolo en la experiencia, padeciéndolo con paciencia. Como dice Hegel: "De una parte, no hay más remedio que resignarse a la largura de este camino, en el que cada momento es necesario - de otra parte, hay que detenerse en cada momento, ya que cada uno de ellos constituye de por sí una figura total individual [...]" (PhdG, p. 25). La Fenomenología del Espíritu no se comprende a sí misma como una filosofía que simplemente pone su objeto, no es simplemente eine vorstellende Philosophie. Si lo pone, lo hace para negar esa posición. En la clase de posición representada por la Fenomenología, ella no pone su objeto para contemplar o considerarlo -en esto Hegel ya no es griego- sino que ella es una filosofía que junto con poner su objeto se pone a sí misma en él, en la conciencia, deviniendo ésta objeto de sí misma, o sea, poniéndose a sí misma como objeto.

Pero el objeto como tal no solo se enfrenta o es resistente a su "reducción en la conciencia", sino que diverso. Por lo tanto, diversa es también la forma de resistencia que él ofrece. Esas diversas formas de resistencia son las que obedecen, en líneas generales, a los tres niveles de la conciencia. Estos tres niveles se especifican por la diversidad del objeto. La diversidad del objeto no alude a que se trate aquí tan solo de diversos objetos; se trata también del mismo objeto en su diversidad: el primero es el de la conciencia como tal (Bewußtsein überhaupt); el segundo corresponde a la autoconciencia (Selbstbewußtsein); y el tercero a la razón (Vernunft). Al primer nivel le corresponde el ser; al segundo, la esencia; al tercero, el concepto. Es preciso tener presente cómo estos tres niveles se ordenan respecto del objeto. Esos respectos ordenadores son correlativamente: el ente; la reflexión sobre sí misma que efectúa la conciencia; y, finalmente, la reunión de conciencia y autoconciencia.

Por otra parte, la misma Selbstanzeige antes mencionada inicia la presentación expresando que el volumen en cuestión "stellt das werdende Wissen dar" (Selbstanzeige, p. 446) "expone el saber en devenir", el saber que deviene o llega a ser; se podría decir, en fórmula técnica: el saber in fieri. Este especial modo de devenir -porque aquí no deviene cualquier cosa sino el saber- es , por tratarse de la Fenomenología, un manifestarse del saber. El saber no está ya dado, y, en consecuencia, tampoco puede ser alcanzado como quien apunta con un arma a un blanco previamente determinado. La presuntiva arma del conocimiento, que pasaría así a convertirse en un instrumento, no nos sirve. No hay para Hegel una suerte de pistoletazo que diera, de un solo disparo, en el blanco del saber absoluto. Por eso, Hegel precisa en este punto: "Este llegar a ser -el devenir de la ciencia- tal como habrá de revelarse en su contenido y en las figuras que se muestran en él, no será lo que de inmediato se presenta bajo una introducción de la conciencia acientífica a la ciencia, y será también algo distinto de la fundamentación de la ciencia -así nada tendrá que ver con el entusiasmo que comienza inmediatamente con el saber absoluto como un pistoletazo y se desembaraza de los otros puntos de vista declarando que no quiere saber nada de ellos" ( $P h d G$, 
p. 24$)^{24}$. Un pistoletazo sería ciertamente entusiasmante, y uno tal lo ha representado siempre la intuición que, como tal, mutatis mutandis, según las distintas filosofías, se caracteriza por la inmediación en el acceso a sus objetos.

En la Selbstanzeige se destaca, además, que "ella [la Fenomenología del Espíritu] considera la preparación a la ciencia desde un punto de vista mediante el cual es una nueva, interesante y la primera ciencia de la filosofía" (Selbstanzeige, p. 446). Pese a todo nuevo comienzo del filosofar, las Meditaciones de Descartes siguen siendo, como lo indica su título original, Meditationes de prima philosophia, tal como Aristóteles pretendió determinar a ésta en los libros compendiados con el nombre de tà metà tà physiká. Hegel habla, por su parte, como se acaba de ver, de "primera ciencia de la filosofía". Esta primariedad es doble, por una parte, es inicial y, por otra, especulativa, pues en ella el resultado ya se contiene -aunque aún no ex-puesto- en su comienzo ${ }^{25}$.

La fenomenología del espíritu, como primera ciencia de la filosofía es Wissenschaft der Erfahrung des Bewußtseins, Ciencia de la experiencia de la

$24 \quad$ "Dieses Werden, wie es in seinem Inhalte und den Gestalten, die sich in ihm zeigen, sich aufstellen wird, wird nicht das sein, was man zunächst unter einer Anleitung des unwissenschaftlichen Bewußtseins zur Wissenschaft sich vorstellt, auch etwas anderes als die Begründung der Wissenschaft, -so ohnehin als die Begeisterung, die wie aus der Pistole mit dem absoluten Wissen unmittelbar anfängt und mit anderen Standpunkten dadurch schon fertig ist, daß sie keine Notiz davon zu nehmen erklärt".

25 El texto de la Sebstanzeige sigue a continuación diciendo que la Fenomenología "comprende en sí las diversas figuras del espíritu como estaciones del camino, mediante las cuales él deviene saber puro o espíritu absoluto. Por eso, en los capítulos principales de esta ciencia, que se divide nuevamente en otros más, se considera la conciencia, la autoconciencia, la razón observadora y actuante, del espíritu mismo, entendido como espíritu ético, formado y moral, y finalmente considerado como [espíritu] religioso en sus diversas formas. El reino de las manifestaciones del espíritu que se ofrece a primera vista como caos, es expuesto en un orden científico, que ella expone según su necesidad, en que se disuelven los incompletos y transitan a los superiores, que son su verdad próxima. La última verdad ellas la encuentran finalmente en la religión y luego en la ciencia, como el resultado del todo". El texto completo de la Selbstanzeige-muy breve- es el siguiente: "Dieser Band stellt das werdende Wissen dar. Die Phänomenologie des Geistes soll an die Stelle der psychologischen Erklärungen oder auch der abstrakteren Erörterungen über die Begründung des Wissens treten. Sie betrachtet die Vorbereitung zur Wissenschaft aus einem Gesichtspunkte, wodurch sie eine neue, interessante, und die erste Wissenschaft der Philosophie ist. Sie faßt die verschiedenen Gestalten des Geistes als Stationen des Weges in sich, durch welchen er reines Wissen oder absoluter Geist wird. Es wird daher in den Hauptabteilungen dieser Wissenschaft, die wieder in mehrere zerfallen, das Bewußtsein, das Selbstbewußtsein, die beobachtende und handelnde Vernunft, der Geist selbst, als sittlicher, gebildeter und moralischer Geist, und endlich als religiöser in seinen unterschiedenen Formen betrachtet. Der dem ersten Blick sich als Chaos darbietende Reichtum der Erscheinungen des Geistes ist in eine wissenschaftliche Ordnung gebracht, welche sie nach ihrer Notwendigkeit darstellt, in der die unvollkommenen sich auflösen 
conciencia ${ }^{26}$. Acudiendo a lo que denomina "un episodio lingüístico", Ortega y Gasset sostiene que "experiencia, empeiría es una palabra que en griego, como en latín, vive de la raíz per. Los vocablos, como las plantas viven de sus raíces. En las lenguas germánicas existe igualmente per en forma de fahr. Por eso, experiencia se dice 'Erfahrung"' (Ortega 1979, pp. 148-149). Lo interesante de estas observaciones de Ortega no radica tanto en las similitudes en los étimos que pueden hallarse entre empeiría, experiencia y Erfahrung, cuanto más bien en que sus reflexiones echan de ver, no una palabra, sino a través de la palabra, un elemento común a todas las lenguas del caso; me refiero a la idea de peligro: en griego, peira; en latín, periculum; en alemán, Gefahr; palabras todas en último término emparentadas. Esta idea de peligro, como formando parte esencial de la Erfahrung, está íntimamente presente en la experiencia incluso hasta el punto de conconstituirla. Quien se pone en la vía ${ }^{27}$ de la experiencia está expuesto a correr peligro, a veces incluso a zozobrar, pero al mismo tiempo puede en ese escenario ganarse a sí propio en la experimentación purificante del verdadero sabor de las cosas, vale decir, del verdadero saber acerca de ellas. Si en Kant, el engaño se produce al nivel de la razón, en Hegel lo es al nivel de la sensibilidad. A este respecto, sin que ello sea excluyente, el filósofo de Stuttgart

und in höhere übergehen, welche ihre nächste Wahrheit sind. Die letzte Wahrheit finden sie zunächst in der Religion und dann in der Wissenschaft, als dem Resultate des Ganzen".

"In der Vorrede erklärt sich der Verfasser über das, was ihm Bedürfnis der Philosophie auf ihrem jetzigen Standpunkte zu sein scheint; ferner über die Anmaßung und den Unfug der philosophischen Formeln, der gegenwärtig die Philosophie herabwürdigt, und über das, worauf es überhaupt bei ihr und ihrem Studium ankommt".

26 Hegel había anunciado repetidamente que publicaría su Sistema de Filosofía. Ello tiene lugar, sin embargo, sin mencionar explícitamente a la Fenomenología. Esa mención tiene lugar en el invierno de 1806-1807 al ser avisada la lección que habría de dictar en el semestre correspondiente. El aviso rezaba: Logicam et Metaphysicam s. Philosophiam speculativam praemissa Phaenomenologia mentis ex libri sui: System der Wissenschaft, proxime proditura parte prima [...]. En este sentido, la Fenomenología del Espíritu estaba subordinada en su intención primaria y primera al sistema de la ciencia. Vale decir, más allá de la discusión en cuanto a la integración definitiva de la obra al sistema, Hegel entiende que la Fenomenología debía ser momento constitutivo de él, y, a saber, como su primera parte. Así, en la hoja del título de la obra, según la primera edición, se consigna el epígrafe: System der Wissenschaft. Más abajo, luego de indicarse el autor y sus títulos académicos, se agrega lo que los editores hoy denominan Zwischentitel: Ersther Teil, die Phänomenologie des Geistes. La ya famosa expresión Wissenschaft der Erfahrung des Bewusstseins se encuentra entre el Prólogo y la Introducción, pero ello correspondería sin embargo, a la primera intención de Hegel, pues hoy se sabe que éste "había dado instrucciones al encuadernador de sustituir el primer subtítulo, que correspondía a su concepción original, por el segundo, que hizo imprimir al terminar de escribir su libro" (De la Maza, M. 2004, quien se apoya a su vez en F. Nicolini y su artículo: "Zum Titelproblem der Phänomenologie des Geistes”, en Hegel-Studien, 1967, pp. 113-123).

27 La experiencia es - como lo recuerda también Ortega- una vía, se trata necesariamente de un hodós, aunque sin méthodos (cfr. op. cit., p. 150). 
está más cerca de Descartes que de Kant. A su manera, también en Descartes hay una fenomenología del espíritu, un saber que va depurándose desde lo sensible a lo espiritual o racional. La diferencia estriba, eso sí, en que mientras que en Descartes se produce una desconexión, una Ausschaltung diría Husserl, de las distintas regiones de la conciencia, en la Fenomenología hay elevación superadora conservadora de las formas del saber solo aparentemente deficientes.

Como la conciencia no sabe primero nada, cuando comienza a hacer la experiencia, es en cierto modo y hasta cierto punto escéptica, y quiere comprobar por sí misma la verdad. La comprobación acontece aquí por vía de probación, pero no probación lógico-argumentativa, sino "a modo de pasión". De allí que probar por sí misma la verdad significa para la conciencia ante todo probarse a sí misma, padeciéndola, o sea, padeciéndose. En el contexto filosófico hegeliano hay la sugerencia de un "hacer la experiencia", en el sentido de "hacer la prueba". La conciencia debe hacer la prueba experiencial, su propia experiencia para devenir ciencia de la experiencia de la conciencia. Hablando de un modo impropio, "en un principio", la conciencia no tiene nada que probar, no porque no tenga nada que probar, sino porque nada tiene. Prueba se dice en latín periculum; la conciencia debe peligrar, pasar peligros, atravesando el páthos de la experiencia. El contenido de este viaje periculoso, peligroso que es la experiencia, eine gefährliche Fahr, es un viaje lleno de contenido y vicisitudes que experimenta la conciencia, "prouver et éprouver" (Ortega, op. cit., p. 152). Este viaje no es peligroso por estar lleno de peligros, sino por ser viaje; el predicado "peligroso" (gefährlich) está ya en el sujeto "viaje" (Fahr). Lo peligroso, dicho en la terminología de Kant, es analítico respecto del viaje.

"El gran teatro del mundo" de la exposición de la verdad filosófica es la experiencia. Por eso, dice Hegel, en bello resumen de las ideas planteadas: "nada es conscientemente-sabido que no esté en la experiencia o, como se expresa también esto, que no esté presente como verdad sentida, como lo eterno internamente revelado, como lo sagrado en que se cree, o de cualquier otro modo en que se exprese. Pues la experiencia es precisamente esto, que el contenido -que es el espíritu- sea en si substancia y, por tanto, objeto de la conciencia. Pero esta substancia que es el espíritu en su devenir hacia lo que él es en sí y recién como este devenir en su devenir que se refleja en sí, es, en verdad, el espíritu. Es en sí el movimiento que es el conocer - la transformación de aquel en sí en el para sí, de la substancia en el sujeto, del objeto de la conciencia en objeto de la autoconciencia, es decir, en un objeto asimismo superado o en el concepto. Este movimiento es el círculo que retorna a sí, que presupone su comienzo y sólo lo alcanza en el final" (PhdG, p. 429) ${ }^{28}$.

"Es muß aus diesem Grunde gesagt werden, daß nichts gewußt wird, was nicht in der Erfahrung ist oder, wie dasselbe auch ausgedrückt wird, was nicht als gefühlte Wahrheit, als innerlich geoffenbartes Ewiges, als geglaubtes Heiliges, oder welche Ausdrücke sonst gebraucht werden, vorhanden ist. Denn die Erfahrung ist eben dies, daß der Inhalt - und er ist der Geist - an sich, Substanz und also Gegenstand des Bewußtseins ist. Diese Substanz aber, die der Geist ist, ist das Werden seiner zu dem, was er an sich ist; und erst als 
En virtud de sus configuraciones dialécticamente producidas, el saber se hace concreto. Resulta extraño este volverse concreto si se piensa que la conciencia va de camino al concepto. Pero los distintos momentos configurativos se van ganando precisamente en la medida de su concreción. Concreto es lo que ha crecido con, en compañía de..., concretos son los hermanos, p. ej., porque y en la medida en que han crecido juntos, y no solo porque son individuos. En la Fenomenología, las diversas figuras de la conciencia se ganan cooperativamente, vale decir, con-cretamente, "concrecientemente". En la concreción hegeliana no resuena tanto la individuación ni la particularización, cuanto más bien el sýnolon. Cada parte se gana no aisladamente, sino en unidad con otro, sýn-hólon. El despliegue del sistema filosófico es en sí mismo experiencia. Hegel dice de la experiencia que ella es "dialektische Bewegung, welche das Bewußtsein an ihm selbst [...] ausübt" (PhdG, p. 60), "movimiento dialéctico que la conciencia ejerce en ella misma”.

\section{Conclusión}

Con estas observaciones, que determinan la concepción fundamental en la base de la Fenomenología del Espíritu, Hegel establece de antemano la labor de esta obra, en lo que toca al sentido y alcance de su puesta en escena o ejecución. Como puede verse especialmente en la primera parte de la obra, dedicada a la conciencia que sabe ingenuamente sus objetos, pero también en otros momentos más abarcadores de la misma, como el prefacio y la introducción, la fenomenología muestra, por una parte, a una conciencia esencialmente dependiente de los avatares del tiempo y del espacio, una conciencia volcada irreflexiva, ingenuamente hacia sus objetos. Se trata allí de una conciencia aún no iluminada por la reflexión, sino naturalmente presa de lo que Ernst Bloch, a propósito de otra cosa, llamaba la "oscuridad del instante vivido", “der Dunkel des gelebten Augenblicks" (cfr. Fulda 2003, p. 83.) ${ }^{29}$. El Augenblick es el golpe de mirada del ojo. El ojo mira solo un instante. Funcionalmente, el ojo es instante, Augen-blick. La conciencia como una suerte de ojo del instante se absorbe en su objeto viviendo solo en él, a tal punto que ni siquiera sabe que éste es suyo, sabe pero no sabiendo que sabe; sabe su objeto al precio de perderse ella misma en sí misma, es justamente una conciencia ensimismada, y a fuer de ensimismada, enajenada, porque el ensimismamiento puede ser la forma más grave de enajenación. La oscuridad del

dies sich in sich reflektierende Werden ist er an sich in Wahrheit der Geist. Er ist an sich die Bewegung, die das Erkennen ist, - die Verwandlung jenes Ansichs in das Fürsich, der Substanz in das Subjekt, des Gegenstandes des Bewußtseins in Gegenstand des Selbstbewußtseins, d.h. in ebensosehr aufgehobenen Gegenstand oder in den Begriff. Sie ist der in sich zurückgehende Kreis, der seinen Anfang voraussetzt und ihn nur im Ende erreicht”.

29 La expresión alude a que no solo los individuos, sino también la humanidad experimentan muchas veces la existencia como un acontecimiento, sin barruntar siquiera que ese instante está preñado de consecuencias para el presente y el futuro. 
instante no vale solo de la certeza sensible, sino también del entendimiento. Ya dentro de la sección de la autoconciencia, Hegel indica, en efecto, que "sólo en la autoconciencia, como concepto del espíritu, tiene la conciencia su punto de viraje, a partir del cual marcha desde el brillo coloreado del más acá sensible y de la noche vacía del más allá suprasensible hacia el día espiritual de la presencia" (PhdG, pp. 108-109) ${ }^{30}$.

Ahora bien, a esta absorción oscurecedora de los meros instantes que podría acabar en escepticismo se opone la especulación, la que es esencialmente móvil y propia de la dialéctica. El método dialéctico se destaca esencialmente del escepticismo. En cierto sentido, o al menos a primera vista, en el escepticismo se muestra operando también una suerte de dialéctica, pues, al menos para Hegel, la base del escepticismo es el reconocimiento del momento en la experiencia en que concepto y objeto no concuerdan. A partir de aquí, el escepticismo concluye que así no puede llegar a conocerse objeto alguno. En este sentido, el escepticismo nos instala en un saber puramente negativo. En palabras de Hegel, es característico del escepticismo que "vea en el resultado sólo la nada pura y abstrae del hecho de que esta nada determina la nada de aquello de lo que resulta" (PhdG, p. 57) ${ }^{31}$. O sea, el escepticismo no comprende que la negatividad o la nada es un elemento del proceso de comprensión, pero no su condición. El escepticismo surge de la contemplación porque ésta es eminentemente objetual. En ella ponemos lo otro justamente como ob-jeto, como Gegen-stand, como lo que se le enfrenta. En la especulación, en cambio, la posible visión se produce no por contemplación, sino por re-flexión, por reflejo en el otro, se trata de una suerte de ojo que se ve a sí mismo en otro que logra reflejarlo, como en un speculum. La especulación, en tanto que reflexión, es la única manera de salir de la deslumbrante claridad, enceguecedora, del "instante vivido". En la filosofía especulativa, lo que no se alcanza a ver en sí mismo se logra atisbar en otro, por eso es especular y espectacular. Podría hablarse igualmente de una especie de repliegue. Este repliegue es la reflexión, que también evoca el mismo carácter especular en la idea de reflejo.

Cuenta H.-G. Gadamer que sobre un dintel en la cabaña de Heidegger en la Selva Negra estaba escrito el dicho de Heráclito "todo lo gobierna el rayo" - y esto quería decir: "No el eterno fuego, no el supremo Dios, que truena desde el Olimpo cuando algo no ha podido realizarse según su voluntad, sino más bien el rayo, que por un largo instante nos abre repentinamente la oscuridad que nos rodea, antes de que se cierre en torno a nosotros una tal aún más profunda" (Gadamer 1991, p. 34). Estas palabras pueden ser interpretadas, por cierto, en cercanía del páthos heideggeriano, en referencia al velo (Schleier) que cubre el ser; pero quizá no es necesario ir tan lejos:

30 "Das Bewußtsein hat erst in dem Selbstbewußtsein, als dem Begriffe des Geistes, seinen Wendungspunkt, auf dem es aus dem farbigen Scheine des sinnlichen Diesseits und aus der leeren Nacht des übersinnlichen Jenseits in den geistigen Tag der Gegenwart einschreitet".

31 "Sie ist nämlich der Skeptizismus, der in dem Resultate nur immer das reine Nichts sieht und davon abstrahiert, daß dies Nichts bestimmt das Nichts dessen ist, woraus es resultiert". 
también la conciencia de la certeza sensible, p. ej., tiene su instante de luz. Aunque aferrada a su objeto, éste, por su propia identidad se contrapone resistiéndosele y se escapa hundiéndose para siempre en la calígine finita de su primera aparición. Esta opacidad, profunda oscuridad, profunda opacidad en esa su primera aparición, deviene luz desde su negación, en la que cobra una figura nueva. Esta oscuridad es superadora en tanto superada por un nuevo rayo, un rayo negativo, dialéctico que transforma la ya luminosa oscuridad del instante presente, sin tiempo realmente, en una nueva iluminación. "El momento dialéctico -escribe Hegel en la Enciclopedia (1827) - es el propio autoeliminarse de tales determinaciones y su tránsito a las que le son contrapuestas" (EphW, $\S 81$, p. 91) ${ }^{32}$. Por su parte, en la Fenomenología se dice: "Este movimiento dialéctico, que la conciencia ejerce tanto en su saber como en su objeto, en cuanto brota para ella desde allí el nuevo objeto verdadero, es propiamente lo que se llama experiencia" (PhdG, p. 60) ${ }^{33}$.

La 'dialéctica especulativa' es, según Heidegger, simplemente 'el método'. Con este término no se mienta ni un instrumento del representar ni solo una especial manera de proceder de la filosofía. 'El método' es el movimiento interno de la subjetividad, 'el alma del ser', el proceso de producción, mediante el cual se teje la trama del todo de la realidad efectiva del absoluto" (Heidegger 1996, p. 432). La dialéctica entera es así un juego de iluminaciones y apagones recíprocos, pues: tà dè pánta oiakízei keraunós, todo lo gobierna el rayo (DK, Fr. 64).

\section{Referencias bibliográficas}

\section{Obras de Hegel}

PhdG: Hauptwerke in sechs Bänden, Phänomenologie des Geistes. vol. 2, Felix Meiner, Hamburg, 1999.

WdL: Hauptwerke in sechs Bänden, Wissenschaft der Logik, vol. 3, Felix Meiner, Hamburg, 1999.

VGPh:Werke in zwanzig Bänden, Vorlesungen über die Geschichte der Philosophie III, Band XX. Theorie-Werkausgabe. Redaktion: Eva Moldenhauer und Karl Markus Michel, Frankfurt 1969-1971.

EphW:Gesammelte Werke in Verbindung mit der Deutschen Forschungsgemeinschaft; hrsg. v. der Nordrhein-Westfälischen Akademie der Wissenschaften, Band 19

32 "Das dialektische Moment ist das eigene Sich-Aufheben solcher Bestimmungen und ihr Uebergehen in ihre entgegengesetzte".

33 "Diese dialektische Bewegung, welche das Bewußtsein an ihm selbst, sowohl an seinem Wissen als an seinem Gegenstande ausübt, insofern ihm der neue wahre Gegenstand daraus entspringt, ist eigentlich dasjenige, was Erfahrung genannt wird". 
Enzyklopädie der philosophischen Wissenschaften im Grundrisse (1827) hrsg. von W. Bonsiepen und H-C. Lucas, F. Meiner, Hamburg, 1989.

Fenomenología del Espíritu. Trad. W. Roces, Fondo de Cultura Económica. México: 1966.

Fenomenología del Espíritu. Edición y traducción de Manuel Jiménez Redondo. PreTextos: Valencia, 2006.

\section{BibLIOGRAFÍA SECUNDARIA}

De la Maza, M. (2004), Lógica, Metafísica, Fenomenología. La Fenomenología del Espíritu de Hegel como introducción a la Filosofía especulativa. Santiago de Chile: Eds. Universidad Católica de Chile.

Descartes, René (AT) (1982), Oeuvres complètes publiées par Charles Adam et Paul Tannery, Tomo VII. Paris : Vrin.

Dri, Rubén (2006²). La fenomenología del espíritu de Hegel. Bs. Aires: Ed. Biblos.

Fulda, H. F. (2003). Hegel, München: Verlag C.H. Beck.

Gadamer, H.-G.(1991), "Hegel und Heraklit”, Gesammelte Werke, Band 7, Griechische Philosophie III. Stuttgart: Mohr Siebeck.

Heidegger, Martin $\left(1986^{16}\right)$. Sein und Zeit. Tübingen: M. Niemeyer Verlag.

(1996). "Hegel und die Griechen", en, Wegmarken, Frankfurt am Main: Vittorio Klostermann.

Hermann Diels, Walther Kranz, eds. y trads. (DK). Die Fragmente der Vorsokratiker Griechisch/Deutsch. 3 Bände. Zürich: Weidmann, Zürich.

Hyppolite, Jean (1961²), Logique et Existence. Paris: PUF.

KrV: Kant, Immanuel (1998), Kritik der reinen Vernunft. Hamburg: F. Meiner.

Ortega y Gasset, José (1979), La idea de principio en Leibniz y la evolución de la teoría deductiva. Madrid: Alianza Editorial.

Platón (1981), República. Madrid: Centro de Estudios Constitucionales.

Scholz, Heinrich (1931), "Über das Cogito, ergo sum”. Kant-Studien, 36: 127-147.

Wiedmann, Franz (1965), Georg Wilhelm Friedrich Hegel in Selbstzeugnissen und Bilddokumenten. Reinbeck bei Hamburg: Rohwolt.

Zubiri, X. (1994), Los problemas fundamentales de la metafisica occidental. Madrid: Alianza Editorial. 